\title{
Exploration and Thinking on the Teaching Model of Theory and Practice for Mechanical Engineering "Excellence Engineer Training Plan”
}

\author{
Sui Xiulin \\ College of Mechanical and Power Engineering \\ Harbin University of Science and Technology \\ Harbin, China \\ suixiulin@sina.com
}

\author{
Shao Junpeng, Yu Yanqiu \\ College of Mechanical and Power Engineering \\ Harbin University of Science and Technology \\ Harbin, China \\ sjp566@sina.com
}

\begin{abstract}
Excellence engineer education training plan is aimed at training a number of high quality engineering and technical personnel with innovative ability adapt to the needs of economic and social development. The teaching model of theory and practice for mechanical engineering excellence engineer training plan and implementation effect are discussed. The plan of excellent engineers training should focus on the cultivation of "good quality, quick, innovation, good start" of the future outstanding mechanical engineer, to develop the "Engineering", "innovation" objectives.
\end{abstract}

Keywords- excellent engineer education; training plan; mechanical engineer; teaching model

\section{INTRODUCTION}

"Excellence engineer education training plan" is to implement the new path of industrialization with Chinese characteristics, the construction of innovative country, a country rich in human resources strategic plan, implement the "national medium and long-term educational reform and development plan (2010-2020)" and "country long-term talent development plan outline (2010-2020)" of the major reform projects, but also to promote China's engineering education country to a powerful country of the significant move of engineering education [1].

As the second batch of " Excellence engineer education training plan " of the Ministry of education, Harbin University of Science and Technology majored in mechanical engineering has been actively exploring in depth in the excellence engineer training plan base, the students practice, signed the " excellence engineer plan" practice base agreement, students training cooperation agreement and the enterprise, training program, curriculum system, practice training, graduation design in-depth practice in talent, explore between national development, enterprise needs, personnel training and students desire to contact and conflict, culture of good school to transition enterprises, to develop the "Engineering", "innovative" talent, conducted very fruitful exploration to promote the "in-depth implementation of training plan of excellent engineer education".

\section{MECHANICAL PROFESSIONAL IMPLEMENTATION OF "EXCELLENT ENGINEER PLAN" GUIDING IDEOLOGY}

To set up the comprehensive development and diversification of the concept of talent; establish a national strategy for active service, active service demand of industry enterprise concept. The reform and innovation of training mode of talents in high engineering education, improve the quality of high engineering education, the new mechanism of colleges and enterprises founded joint personnel training, efforts to improve their service to the nation and the people's sense of social responsibility, the courage to explore the spirit of innovation and good at problem solving ability in practice [2]. Through the investigation of mechanical engineering and automation professional development and talent demand, the excellence Engineer training plan for specialty of mechanical design \& manufacture of Harbin University of Science and Technology is formulated, with the scientific outlook on development as guidance, to return to engineering practice as the focus, in order to improve the students' engineering practice ability as the breakthrough, school-enterprise cooperation, mechanism innovation, strengthening practice, highlight the characteristics, and actively explore effective ways of cultivating future outstanding mechanical engineers with the characteristics of "good quality, quick, innovation and good start" .

\section{MECHANICAL PROFESSIONAL "EXCELLENT ENGINEER PLAN" PERSONNEL TRAINING GOAL}

Through the close cooperation of education and industry, universities and enterprises, taking the actual project as the background, taking engineering as the main line, focus on improving the students' consciousness of engineering, engineering quality and engineering practice ability of [3], through the implementation of "training plan" excellent engineers, develop its solid foundation theory and professional knowledge, have stronger engineering practice ability, innovation consciousness and good comprehensive quality, the coordinated development of knowledge, ability, quality, virtue, wisdom, body, beauty comprehensive development, grasp and machinery related to the natural science and the humanities and social sciences knowledge, master the mechanical engineering discipline basic theory and professional knowledge and Application, with strong ability of engineering practice, design ability and innovation 
ability, can be engaged in the design of mechanical engineering and automation in the field of manufacturing, technology development, application research, operation and management work should be used in talent and technology advanced engineering, cultivating a large number of innovative ability, Really meet the outstanding mechanical engineer machinery industry and enterprise development needs.

\section{MECHANICAL PROFESSIONAL " EXCELLENT ENGINEER PLAN" PRINCIPLE}

(1) Achieved the purpose of knowledge, ability and quality of the coordinated development. In the curriculum system, strengthening the relevant engineering and technology of public basic knowledge, technology and professional knowledge, to create a workplace atmosphere and environment, combining class experimental teaching and extracurricular practice, especially in the professional courses, focusing on product, process or system design, design, implementation and operation the new design, curriculum system, reconsider the courses, to organize the teaching process, reducing class hours, increase the content of practice, increase students' extracurricular learning and practice time.

(2) The reform of the teaching mode, teaching content update. Strengthen the construction of education platform, engineering practice base construction and the construction of teachers' team, inherit and carry forward the engineering education pattern with characteristics of Harbin University of Science and Technology, established engineering education system, effective quality evaluation and supervision mechanism, to adapt to the demand of the construction of national and regional economy, training excellent mechanical engineer for the socialist modernization construction in China, has the ability of international vision and innovation.

(3) Changing the knowledge transferring process and method. On teaching contents and methods, declarative knowledge transfer from the primary change to acquire procedural knowledge. Mainly includes the process of thinking, understanding and expression of the exchange process, process of exploration, experiment, the design process, manufacturing process, and test process. This kind of knowledge can't be almost obtained from the classroom or books, only through the scientific system of practice to master some knowledge, some knowledge only to the factory or business practice to cognition.

(4) Strengthening the cultivation of practice ability. The reasonable arrangement of practice teaching in class and after class, school and extracurricular practice base outside school, stable set up multi-level, high standard, comprehensive practice teaching system, construction of more than one step by step. Creating a competitive, independent learning and practice in the process of cultivation of the workplace environment, enable students to "learn by doing", to better grasp the theoretical knowledge, enhance the knowledge application ability of practice.

(5) Strengthening the education of comprehensive quality and ability. In the installation and training course, with particular attention to the comprehensive quality of students training, establish a correct outlook on life and values, establish basic social moral right, and pay attention to the cultivation of thinking and behavior, interpersonal, teamwork. Students' basic individual ability, comprehensive ability and interpersonal skills will be trained.

\section{MECHANICAL PROFESSIONAL " EXCELLENT ENGINEER PLAN" CURRICULUM SYSTEM}

The excellent engineer training program for specialty of mechanical design \& Manufacture of Harbin University of Science and Technology is based on the school teaching and training system. According to Schools "excellent idea of the overall work of the engineer training program", Especially for the "humanistic quality, the awareness of environmental protection and sustainable development, lifelong learning and knowledge creation capability, organizational management and team leadership skills, strategic thinking ability, expression and high level engineering communication skills, engineering ethics and international competitiveness" of the training goal of [4], established the "three platform, teaching system the two phase, four modules", "Excellent engineer training scheme" undergraduate program for applied talents include two parts of learning in school and enterprise, the two phase of the study were the development of corresponding professional school training plan and enterprise training plan.

\section{A. Reconstruction curriculum system, focusing on innovation and application training}

Reconstruction of professional curriculum system, reduction theory hours, increasing practice hours, strengthening practice teaching.Students in the natural sciences, humanities, social sciences and mechanical disciplines to lay a solid foundation in the first, the two year; Strengthen practical and advanced specialized courses in the third year, according to the needs of the enterprise and has four professional direction module combined with professional features The A module for the modern design technology module, $\mathrm{B}$ module for the manufacture of machinery and automation module, $\mathrm{C}$ module for the mold design and manufacturing module, $\mathrm{D}$ module for electrical control technology module. Reasonable integration of teaching content and professional direction of each module lesson Joint Enterprises, reflect business needs, focusing on the cultivation of students' innovation and application; while increasing professional seminars and corporate teaching links, by the corporate practice of experienced engineers and technicians for students the scene teaching, enable students to gain insight into the actual business.

\section{B. Aspects of the practice of reform, highlighting the engineering practice ability cultivation}

Compression and deletion of a strong practical curriculum design content for different professional direction, namely the establishment of modern design, advanced manufacturing, mechanical and electrical control and mold design and manufacture of integrated design training sessions, students comprehensive design capabilities to solve 
practical problems and practical ability; creation of an open and innovative experiments to improve students 'practical ability and innovation consciousness; establishment of a skills training practice links, and enhance students' ability of engineering practice.

\section{Enhance students' extra-curricular practice} environment, and improve the overall quality of students and the practical ability

The set corporate research and internships, CNC machining skills training, engineering software applications training, extracurricular technological innovation activities, competitions and other extra-curricular practice links, and set the extracurricular credits. CNC Machining skills of students, such as engineering software application skills certification training, professional skills certification training available CNC machining skills, the Auto CAD global certification certificate; established the group of students in science and technology innovation to give strong support in the capital, places, enable students to actively participate in the activities of scientific and technological innovation, and homemade laboratory equipment, organizing students to participate in various competitions; encourage students to take advantage of the holidays and spare time to participate in corporate research and internship activities, further increasing the adaptation and understanding of enterprise engineering environment.

\section{Develop effective corporate learning programs to improve the quality of students industrialized}

Make full use of the platform of the school-enterprise cooperation, to build an open system for mechanical engineering talents, through a year the enterprise stages of learning and training, so that students get a mechanical engineer professional skills training. To enable students to better understand the organization of production activities to adapt to the enterprise, the attachment phase adopted by enterprises in key sectors rotational training internship training, has developed a detailed enterprise learning content, graduation design uses a project or production system object, project or system development, operation, management carried out by a member of the Steering Group of senior corporate engineering and technical personnel and key teachers. Further strengthen the students' ability of engineering practice, engineering design capability and engineering innovation capability so that it has industrialized qualities.

\section{E. Building students engineering applications with the} ability to innovate comprehensive step-by-step training target practice link

Establishment of " social practice-Cognition practice —Engineering training $\longleftarrow$ School or business skills training —Comprehensive design training_-Business practice -Graduation design" one step by step, comprehensive training in the practice teaching system.

First semester, students through social practice to understand the social and business demand for talents;
The second semester, the cognition practice teaching link will be implemented. The students will visit enterprises, enabling students' preliminary understanding to major in engineering practice;

The third semester, project training practice will be implemented. Students enter the school of engineering training center, through the direct involvement of a series of manufacturing production processes, to enable students to master the skills of Engineering application;

The fourth semester, electrical and electronic practice skill training and practice will be implemented. Through this practice, the students' engineering practice ability has been further improved, and through professional skills certification training and obtained the corresponding occupation qualification certificate;

In fifth, six school term comprehensive design training practice. The link is a student of three years the theory summary and practical application. Through the link to enable students to master the initial mechanical product development and design ability;

In seventh, the eight semester internship and employment practice of enterprises. Students according to the enterprise demand for talent and its own situation, taking employment as the goal, choose the corresponding counterparts enterprises occupation post employment practice, at the same time according to the situation of enterprises completed the graduation design task. In order to business part-time teachers and college full-time teachers under the guidance of students to supplement, the identity of employees, prospective employment status, through the practice and graduation design, its enterprise culture, occupation ethics, comprehensive occupation ability and comprehensive training, improve the students' innovation and entrepreneurial capacity, the ability of Engineering practice.

\section{F. Reform talent evaluation mechanism and manner, focusing on the ability to examine and improve}

In accordance with the characteristics of excellent engineers personnel training, the establishment of the appraisal system with the ability to examine core teaching Steering Group to establish schools and corporate experts, teachers, and students to assess the main, to the quality of teaching, practice teaching, student learning state assess the content of teaching evaluation system, student assessment, detailed assessment indicators, assessment of the student's work attitude, innovation, teamwork, practical skills, professional practice outcomes, focus on observing student engineering practice capacity and ability to innovate, and to ensure the quality of teaching excellence engineer personnel training. 
VI. THE IMPLEMENTATION AND THINKING OF MECHANICAL PROFESSIONAL EXCELLENCE ENGINEERS PLAN

A. Establish a new mechanism for the joint training talents of universities and industry enterprises, strengthen the close cooperation of schools and businesses.

Schools and enterprises form an interdependent relationship, personnel training shared by schools and enterprises, schools are responsible for theoretical teaching, enterprises responsible for the practice of teaching and providing internship for graduates jobs. Through the Joint of Schools and enterprises, Schools have a more comprehensive understanding of the enterprise's demand for talent, help to guide the school's professional curriculum and course contents. Enterprises participate in the training of personnel are conducive to their needs of professional talents, thereby forming enterprises rely on the school survive, source of development. The schools are talent pool for enterprise's development think bank of technological innovation, schools and enterprises win-win situation [5] .Technical personnel of enterprises cooperate with the College assigned instructor during the internship, combine the demand for enterpriser's talented person ability, including the enterprise management, Staff quality, 5S management, equipment operating, enterprise Training of engineering and numerical control technology, computeraided design, Learning the courses theory and practice of technical English, receive a good effect.

B. Creating talent training mode of engineering education, improve students' ability of engineering practice

Use “ $3+1$ " training Mode of Schools and Enterprises Cooperating takes advantage of training applied engineers talents, 3 years to complete the basic education curriculum in schools, professional education courses and elective theoretical courses,1year to complete engineering practice in enterprise, professional practice professional curriculum design and practice link of graduation design. Students give full play to the theory, strong communication skills and other advantages through the internship of various positions in the enterprises. Students' practical ability have great improve, Graduates can reach the basic requirements of a qualified application engineers, can into his new role to the enterprise quickly.

\section{Improve the comprehensive quality of engineering education talents, develop communication and problem-solving skills}

According the requirements of the excellent engineer training plan, the teaching links of theoretical study, practice, curriculum design and graduation design are completed. Good enterprises environment practice the quality and overall of students, cultivate high academic achievers 、 adapt to the engineering and technical personnel in the production needs of fast-paced enterprises [6]. According to the characteristics of the products, combining production research and development needs, School teachers and enterprise engineering and technical personnel jointly formulated graduation design. All of the questions are around to solve technical problems of enterprise and the difficulties of new product development. It were established for the characteristics of graduate design topics Database development project team, mold development projects group, pin machine project group, Device project group, electromechanical motion systems development project group and the process of project group. It takes the combined guidance way by enterprise technical staff and teachers. The students can more quickly into the role of employment, get enterprise recognition and wide acclaim.

\section{The construction of high level engineering education team, improve teachers' practical ability}

According to the requirements of "Excellent engineer plan", strengthen the construction of teachers' team. Build the teacher education base in cooperative enterprise and university, establish mechanism of university teachers to corporation to learning and training, Enterprise engineering and technical personnel to the institutions of higher learning and continuing education, Regular evaluation, training and exchange of teachers and management personnel, comprehensive promotion the teaching ability and level of professional teaching force.

Excellent engineers plan personnel training is still not too mature experience and mode, it must rely on the school and enterprise in-depth exploration and practice, colleges and universities should continue to summarize and accumulated experience, Promote the depth effective implementation of excellent engineers plan, To achieve the purpose of training "Engineering-type" and" Innovative" personnel, Develop "good quality, quick, innovation, good start" of the future outstanding mechanical engineer.

\section{ACKNOWLEDGMENT}

This research was sponsored by Higher Education Science Research Planning Project of Heilongjiang Province.

\section{REFERENCES}

[1] Qingzhu Xu etc, "Excellent engineers plan” as an opportunity to explore engineering personnel training mode reform. vol. 51. Computer Engineering and Science, 2011, pp. 109-111.

[2] SUN Shou-zeng. "Relationship of academic management and administration in universities from power view," vol. 13(1). Journal of Chang'an University(Social Science Edition), 2011, pp. 90-94.

[3] Gaofeng Zhu, "Several concept issues in engineering education”, vol. 01. Research in Higher Engineering Education, 2011, pp. 1-5.

[4] Lijun Wang, Jihuai Li, Yanqing Lu. "Deviation and rational regression of modern engineering education pattern”, vol. 03. Modern education management, 2011, pp. 72-74.

[5] Huiying Bao, Zhiqiang liu, Hongbo Wang. "Exploration and research of machinery applied talents mode" , vol. 02. The development of the western: in middle Journal, 2011, pp. 77-78.

[6] Huang $\mathrm{Xi}$, WenzhenZhang Shiyu Yan. "Research of innovative excellence on engineer training mechanism" . New planning • New Vision - New development - the Seventh Annual Conference, Proceedings of the social science community in Tianjin, Tianjin academiclibrary(center),2011,pp.794-800. 
